Bryn Mawr College

Scholarship, Research, and Creative Work at Bryn Mawr

College

Psychology Faculty Research and Scholarship

Psychology

2015

\title{
Cumulative Contribution of Child Maltreatment to Emotional Experience and Regulatory Intent in Intimate Adult Interactions
}

Sabrina R. Liu

Marc S. Schulz

mschulz@brynmawr.edu

Robert J. Waldinger

Let us know how access to this document benefits you.

Follow this and additional works at: http://repository.brynmawr.edu/psych_pubs

Part of the Psychology Commons

\section{Custom Citation}

Liu, S., Schulz, M.S., \& Waldinger, R.J. "Cumulative Contribution of Child Maltreatment to Emotional Experience and Regulatory Intent in Intimate Adult Interactions." Journal of Aggression, Maltreatment and Trauma 24.6 (2015): 636-655.

This paper is posted at Scholarship, Research, and Creative Work at Bryn Mawr College. http://repository.brynmawr.edu/psych_pubs/36

For more information, please contact repository@brynmawr.edu. 
MALTREATMENT HISTORY, EMOTION, \& REGULATORY INTENT

Final Accepted Manuscript (11/20/14)

\title{
Journal of Aggression, Maltreatment \& Trauma
}

Cumulative Contribution of Child Maltreatment to Emotional Experience and Regulatory Intent in Intimate Adult Interactions

\author{
Sabrina R. Liu ${ }^{\mathrm{a}}$, Marc S. Schulz ${ }^{\mathrm{b}}$, and Robert J. Waldinger ${ }^{\mathrm{a}}$ \\ ${ }^{a}$ Massachusetts General Hospital and Harvard Medical School \\ ${ }^{\mathrm{b}}$ Department of Psychology, Bryn Mawr College
}

Keywords: child maltreatment, couples, video recall, emotion processing, multi type maltreatment, long-term effects, emotion regulation, childhood trauma

This research was supported by the National Institute of Mental Health (K08 MH1555) 
MALTREATMENT HISTORY, EMOTION, \& REGULATORY INTENT

\section{Abstract}

Research and theory suggest that child maltreatment is linked to experiencing heightened levels of negative emotion, greater need to control these emotions, and difficulty in interpersonal relationships as adults. This study examined links between experiencing multiple types of child maltreatment and intentions to control emotion during charged discussions with intimate partners in adulthood, and whether the link is mediated by hostile and sad-anxious emotions. Ninety-seven couples were recruited from the community, with an oversampling of adults with histories of child maltreatment. In addition to reporting on maltreatment history, couples used video recall to rate their level of negative emotions and intention to control emotion during discussions of relationship difficulties with partners. For both genders, number of types of child maltreatment reported was linked with effort to control emotion, and the relationship was partially mediated by the intensity of participants' feelings of hostility. For men, the link was also partially mediated by self-reported sadness and anxiety. Findings underscore the importance in treatment of attending to abuse survivors' experiences of and attempts to manage intense emotions, particularly in couples' therapy.

Keywords: child maltreatment, couples, video recall, emotion processing, multi type maltreatment, long-term effects, emotion regulation, childhood trauma 
MALTREATMENT HISTORY, EMOTION, \& REGULATORY INTENT

Individuals who have been maltreated as children report experiencing more negative emotion as adults, increased reactivity to such emotions, and greater difficulties in interpersonal relationships (Busby, Walker, \& Holman, 2011; Frederick \& Goddard, 2008; Glaser, van Os, Portegijs, \& Myin-Germeys, 2006; Howe \& Campling, 1995; Pollak, Cicchetti, \& Klorman, 1998). Existing research suggests that heightened negative emotion and reactivity leads to increased motivation and efforts to control these emotions (Davis, Levine, Lench, \& Quas, 2010). In spite of the supporting literature, there is a lack of empirical studies that examine the triad of child maltreatment, emotional experience, and efforts at emotion control together in the context of adult interpersonal relationships (Colman \& Widom, 2004; Rellini, Vujanovic, Gilbert, \& Zvolensky, 2012). Current understanding of the interrelationship of these variables relies on our knowledge of links between various pair combinations. This study examines whether individuals with histories of child maltreatment report greater intention to control emotion during affectively-charged discussions with intimate partners and whether this link is mediated by the intensity of negative emotions felt during the interaction.

Research supports links between child maltreatment and interpersonal challenges (Frederick \& Goddard, 2008; Howe \& Campling, 1995). Past studies have shown that maltreated children are more likely to find relationships threatening and painful (Ornduff, 2000) and to attribute hostile intentions to social partners (Dodge, Petit, Bates, \& Valente, 1995). Although few studies to date have focused on maltreated children's intimate relationships in adulthood (Colman \& Widom, 2004), existing research suggests that they are more likely to report relationship problems (DiLillo \& Long, 1999) and negative perceptions of both their partners and the relationship (Mullen, Martin, Anderson, Romans, \& Herbison, 1994; Webb \& Otto Whitmer, 2001). 
MALTREATMENT HISTORY, EMOTION, \& REGULATORY INTENT

Child maltreatment has also been linked to higher rates of divorce in both males and females (Colman \& Widom, 2004).

The ways in which individuals experience and deal with negative emotion may be a key factor underlying links between child maltreatment and interpersonal difficulties in adulthood. Child maltreatment has been linked empirically to the experience of more negative emotions such as fear, anger, and distress (Paivio \& Laurent, 2001; Pollak et al., 1998), as well as many adult psychiatric diagnoses in which negative emotion plays a prominent role, such as depression (Hill, 2006; Wise, Zierler, Krieger, \& Harlow, 2001), anxiety (MacMillan et al., 2001), and posttraumatic stress disorder (Widom, 1999). Along with heightened levels of negative emotion, early maltreatment has also been shown to foster hypersensitivity to negative emotions (Curtis \& Cicchetti, 2013; Luke \& Banerjee, 2012; Masten et al., 2008; Pollack, Cicchetti, Hornung, \& Reed, 2000; Romens \& Pollack, 2012). Such disruption is believed to stem from the experience of growing up in an environment where one's negative emotions are often rejected, punished, or ignored by caregivers (Paivio \& McCulloch, 2004; Shipman et al., 2007) and where there is a lack of models from which to learn how to process different emotions (Walsh, Gonsalves, Scalora, King, \& Hardyman, 2011). As a result, individuals become particularly sensitive to and uncomfortable with the experience of negative emotions (Pollak et al., 2000; Pollak \& Sinha, 2002) and may work harder than non-abused individuals to manage negative emotions in interactions with others.

The idea that maltreatment history is linked to emotion regulatory goals in adulthood is supported by theory and related research, yet the relationship between the two is largely unstudied. It is widely accepted that emotion regulatory efforts are shaped by an individual's goals in particular situations (Campos, Campos, \& Barrett, 1989; Schulz \& Lazarus, 2012; Timmers, 
MALTREATMENT HISTORY, EMOTION, \& REGULATORY INTENT

Fischer, \& Manstead, 1998). However, little is known about the developmental origins of the motivational underpinnings of emotion regulation strategies (Davis et al., 2010). For adults who have experienced child maltreatment, the need or desire to control emotion may come into play particularly during interpersonal conflict. Maltreated individuals often experience heightened levels of emotion during these times, and in response may feel compelled to engage regulatory strategies to minimize their contact with these aversive states (Linehan, 1993; Pavio \& Laurent, 2001).

In an effort to understand further the emotional sequelae of childhood trauma in the context of interpersonal relationships in adulthood, the current study examined whether maltreatment in childhood is linked to participants' intention to control emotions during affectively charged moments of discussions of upsetting events with an intimate partner. Participants' experience of negative emotion during these moments was examined as a possible mediator of this relationship. Based on previous research and theory, it was expected that maltreatment in childhood would be associated with greater motivation to control emotion during affectively-charged interactions and that this association would be mediated by the presence of stronger negative emotions.

The term "child maltreatment" encompasses sexual, physical, and emotional abuse as well as physical and emotional neglect (Bernstein \& Fink, 1998; Bowman, Rew, \& Murphey, 2009). Most maltreated children experience more than one type of abuse and neglect (Kinard, 1994), and there is accumulating evidence that the number of different types of maltreatment experienced may be a critical factor in determining the consequences of maltreatment. For example, a study of maltreatment rates in a community sample found that $43.5 \%$ of participants had experienced more than one of sexual abuse, physical abuse, psychological maltreatment, neglect, 
MALTREATMENT HISTORY, EMOTION, \& REGULATORY INTENT

or witnessing of family violence, as opposed to only $24 \%$ of the sample that had experienced just one type, and 32.5\% who experienced none (Higgins \& McCabe, 2000). These high cooccurrence rates make it difficult to tease out individual effects of various maltreatment forms. Past studies that have found effects for specific types of maltreatment have often failed to assess other forms of abuse and neglect that might have co-occurred (Higgins \& McCabe, 2000; Zlotnick et al., 1996). Yet research supports the idea that different forms of maltreatment have shared consequences for adult psychological functioning (Varia, Abidin, \& Dass, 1996; Widom \& Ames, 1994). Aversive emotional arousal in a less than fully supportive relational context is common across all types of maltreatment and may lead to the employment of maladaptive emotion regulatory strategies (Emery, 1989).

In addition to generating common psychological sequelae, experiencing multiple forms of child maltreatment has a cumulative negative impact on psychological functioning (Clemmons, Walsh, DiLillo, \& Messman-Moore, 2007). Children with histories of multiple types of maltreatment develop more internalizing and externalizing symptoms and have lower social competence than children who experienced just one form of maltreatment (English, Graham, Litrownik, Everson, \& Bangdiwala, 2005, Lau et al., 2005; Rossman, Hughes, \& Hanson, 1998). Similarly, college students with histories of multiple forms of maltreatment display higher levels of depression, suicidality, low self-esteem, substance abuse, and delinquent behavior than those who experience no abuse or just one type of abuse (Arata, Langhinrichsen-Rohling, Bowers, \& O'Farrill-Swails, 2005). Higgins and McCabe (2000) found that adults reporting three to five forms of maltreatment had greater trauma-related symptoms and lower self-esteem than those reporting one or two types of maltreatment. Likewise, the Adverse Childhood Experience Study (ACES), a study of 13,494 adults, found a graded relationship between number of adverse child- 
MALTREATMENT HISTORY, EMOTION, \& REGULATORY INTENT

hood experiences and adult physical and psychological distress (Felitti et al., 1998).

Although using a count of types of maltreatment does not specifically measure severity of maltreatment, the two have repeatedly been found to be highly associated (Clemmons et al., 2007). One study found that number of maltreatment types experienced accounted for $83 \%$ of the variance in level of maltreatment severity (Bowman et al., 2009). Based on these findings, the current study focuses on the relationship between the number of types of childhood maltreatment reported by participants and their emotional experiences and motivation to regulate emotions in challenging discussions with their partners.

An important consideration in studying the interpersonal emotional sequelae of child maltreatment is determining the most appropriate methods for capturing emotion experiences and regulatory goals. Emotion processes unfold and change quickly during interpersonal interactions, requiring methods of study that are temporally sensitive (Schulz and Waldinger, 2010). Commonly-used measures of psychopathology, such as the Diagnostic Inventory for Depression (DID; Zimmerman, Sheeran, \& Young, 2004), the PTSD Symptom Scale-Interview (PSS-I; Foa, Riggs, Dancu, \& Rothbaum, 1993), or the Trauma Symptom Checklist-40 (TSC-40; Briere \& Runtz, 1989; Elliott \& Briere, 1992) - all utilized in recent studies looking at outcomes of multiple forms of child maltreatment (Vranceanu, Hobfoll, \& Johnson, 2006; Clemmons et al., 2007) - include assessments of how respondents generally respond affectively over extended periods of time, but do not specifically capture emotional experiences as they unfold in interactional contexts. Emotion processes in interactions have been captured successfully in the laboratory by asking participants to rate their affective experience while watching a videotape of their emotional encounter soon after it occurred (Gottman \& Levenson, 1985; Ickes, Stinson, Bissonnette, \& Garcia, 1990; Lorber, 2007; Thomas, Fletcher, \& Lange, 1997). The current study builds on this 
MALTREATMENT HISTORY, EMOTION, \& REGULATORY INTENT

cued recall approach, collecting repeated self-reports of participants' emotions and emotion regulatory intentions during emotionally-charged discussions with their partners (Waldinger \& Schulz, 2006).

\section{Method}

\section{Participants}

One hundred nine couples were recruited through advertisements in the Boston metropolitan area. Advertisements on public transportation, in local newspapers, and on flyers posted in public places asked for volunteers to participate in "a study of couple communication." Couples were screened by telephone interview for eligibility; screening included questions about demographics and histories of child maltreatment so that individuals with a history of childhood maltreatment could be oversampled. Eligible couples had to be in a heterosexual relationship, living together for a minimum of 12 months (but not necessarily married) prior to participating in the study, and fluent in English.

The mean age was 33.2 years $(S D$ 8.8) for men and 31.7 years $(S D$ 8.5) for women. The median length of relationship for the couples was 1.9 years; $33.3 \%$ were married, and $78.2 \%$ did not have children. The ethnic makeup of the sample was 58.4\% White, 29.0\% African American, 7.8\% Hispanic, 3.0\% Asian or Pacific Islander, and 2.0\% Native American. The median family income per year was between $\$ 30,000$ and $\$ 45,000$; with $19.3 \%$ of participants indicating that their family earned less than $\$ 15,000$, and $26.0 \%$ indicating that they earned more than $\$ 60,000$. Participants varied widely in their educational experience; $45.0 \%$ had completed a bachelor's or

more advanced degree, $17.0 \%$ had some post-high school education (vocational, some college, or an associate's degree), and 38.0\% had a high school education or less. Rates of child maltreat- 
MALTREATMENT HISTORY, EMOTION, \& REGULATORY INTENT

ment in the sample were as follows: $60(55 \%)$ men and $81(74.3 \%)$ women experienced emotional abuse; $52(47.7 \%)$ men and 60 (55\%) women experienced physical abuse; $28(25.7 \%)$ men and $66(60.6 \%)$ women experienced sexual abuse; $57(52.5 \%)$ men and 77 (70.6\%) women experienced emotional neglect; 48 (44\%) men and 50 (45.9\%) women experienced physical neglect. Informed consent was obtained, and couples were paid $\$ 250$ for their participation. Participants completed questionnaire assessments and the couple interaction task at a first laboratory visit, and completed the video recall portion of the protocol in a second laboratory visit one week later. Twelve participants did not return for the video recall session, resulting in complete data for 97 couples. With respect to number of types of child maltreatment experienced, the 12 women who did not participate $(\mathrm{M}=3.5, \mathrm{SD}=1.88)$ did not differ from the rest of the sample $(\mathrm{M}=3.01$, $\mathrm{SD}=1.69) ; \mathrm{t}(107)=.934, \mathrm{p}=.352$. However, there was a significant difference between men who completed the video recall procedure $(\mathrm{M}=2.11, \mathrm{SD}=1.49)$ and those who did not $(\mathrm{M}=3.42$, $\mathrm{SD}=1.68) ; \mathrm{t}(107)=2.86, \mathrm{p}=.005$.

\section{Procedure}

The research protocol was approved by the Human Subjects Review Committee at Brigham and Women's Hospital, Boston, MA. After providing written informed consent, participants completed questionnaires, including an assessment of prior maltreatment, prior to participating in a couple interaction task and video recall procedure.

Before the interaction task, partners were asked in individual interviews to identify an incident in the past month or two in which their partner did something that frustrated, disappointed, upset, or angered them. Each participant recorded on audiotape a one- or two-sentence statement summarizing the incident and reaction. Partners were then brought together, and, in counterbalanced order, discussed one incident identified by the man and one identified by the woman, each 
MALTREATMENT HISTORY, EMOTION, \& REGULATORY INTENT

for eight minutes. The participant's audiotaped description of each incident was played to initiate discussions, and participants were told to try to come to a better understanding of what occurred.

Approximately one week after the videotaped interactions, each member of the couple returned to the laboratory and participated individually in a video recall procedure consisting of two phases (see details in Schulz \& Waldinger, 2004). Participants viewed the videotape of their interaction and continuously rated their degree of emotional negativity and/or positivity during the interaction with an electronic rating device designed for this study. The device had a knob that moved across an 11-point scale that ranged from very negative to neutral to very positive. Past research has established the validity of this and similar video recall procedures for obtaining reports of affective experience (e.g., Gottman \& Levenson, 1985; Schulz \& Waldinger, 2004; Thomas, Fletcher, \& Lange, 1997).

Using participants' ratings from the first phase of the video recall procedure, six high affect moments (HAMs) were selected for each couple. These included the two 30 -second segments from each discussion in which each partner reported experiencing the most negative emotions, yielding a total of four negative HAMs (two rated as most negative by her and two by him). In addition, the 30-second segment across both interactions that was rated as most positive by each partner was selected, yielding two positive HAMs for the couple. In the second phase of the cued recall task, participants were shown the six HAMs in order of occurrence during the discussion. After viewing each HAM, participants completed questionnaires reporting on their emotions and intentions during that portion of the interaction.

\section{Measures}

Sad-Anxious and Hostile Emotions Aroused during Interaction. The emotion questionnaire completed when watching each 30-second high affect moment asked participants to 
MALTREATMENT HISTORY, EMOTION, \& REGULATORY INTENT

rate how much they felt each of 16 different emotions on a seven-point scale, where "1" represented "not at all" and "7" represented "very much." Because of the particular focus on experience of negative emotions in the current study, 13 of the specific emotions incorporated into the questionnaire were negative emotions. Items were selected to represent at least two dimensions of negative affect found useful in previous research on couple interactions: vulnerable emotions such as sadness and fear, and hostile emotions such as anger and contempt (Schulz \& Waldinger, 2004; Gottman, 1994; Sanford, 2007). Eight items from the Negative Affectivity scale of the Positive and Negative Affect Schedule (PANAS; Watson, Clark, \& Tellgen, 1988) are represented directly or in modified form (e.g., "irritated" rather than "irritable"). Three items found to be important in predicting marital quality and stability in past research were included_- "disgusted," "critical," and "defensive" (Gottman, 1994). Sadness was also added because it was thought to be an important negative emotional experience to capture in the context of couple interactions. Building on previous principal components analyses (Schulz \& Waldinger, 2004), the focus in this study is on two scales: sad-anxious emotions and hostile emotions.

The sad-anxious scale consisted of the following variables: sad, guilty, ashamed, afraid, nervous, and jittery. The hostile emotion scale included the following variables: anger, irritated, disgusted, upset, critical, and defensive. All items in each scale were averaged across the HAMs to create a total score representing the extent to which hostile and sad-anxious emotions were felt throughout the six diverse HAMs. Combining across HAMs improved reliability of the measures. Alpha coefficients of the averaged factors were .86 (men, sad-anxious emotion), .86 (women, sad-anxious emotion), .90 (men, hostile emotion), and .90 (women, hostile emotion), indicating good internal reliability. Evidence for the validity of the HAM emotion scales is provided by the pattern of links between participants' HAM emotion scales and measures of trait 
MALTREATMENT HISTORY, EMOTION, \& REGULATORY INTENT

hostility, depressive symptomatology, and marital satisfaction (Schulz \& Waldinger, 2004).

Intent to control emotion. After reviewing each HAM participants were asked to rate how much they were trying to achieve each of a set of 14 goals during that portion of the interaction, using the same seven-point scale used in the emotion questionnaire. Previous factor analyses identified meaningful groupings of the goals (for a detailed explanation, see Waldinger \& Schulz, 2004), including one related specifically to the regulation of emotion. The Control Emotion factor included the following items: trying to calm self down, trying not to appear weak, trying to calm partner down, and trying to control my anger. The control emotion factor did not differ significantly between positive and negative moments, therefore scale scores were created by averaging the scores from the four items across the six HAMs to capture how much participants were trying to control emotion throughout the affectively intense moments of the interaction.Control Emotion scale scores departed somewhat from a normal distribution, so the scale scores were transformed using a cubed root (Tabachnick \& Fidell, 2001). Alpha coefficients for the averaged scores were .84 for both men and women, indicating good internal reliability.

Childhood Maltreatment. Histories of childhood maltreatment were assessed using the 28-item short form of the Childhood Trauma Questionnaire (CTQ; Bernstein, Fink, Handelsman, \& Foote, 1994). The CTQ has been shown to yield reliable and valid retrospective assessments of childhood maltreatment and neglect (Bernstein et al., 1994; Bernstein et al., 2003). Items on the CTQ ask about five types of maltreatment experiences: sexual maltreatment, physical maltreatment, emotional maltreatment, physical neglect, and emotional neglect in childhood and adolescence (there are five items per type of maltreatment, and three additional questions that correspond to a minimization/denial subscale). Each item is rated on a five-point Likert-type scale with response options ranging from never true (1) to very often true (5). Consistent with previous 
MALTREATMENT HISTORY, EMOTION, \& REGULATORY INTENT

studies (Bowman et al., 2009; Walsh et al., 2011), a variable was created to index the pervasiveness of childhood maltreatment - that is, the number of different types of childhood maltreatment reported by each participant. Dichotomous yes/no variables were determined using the mild to moderate cutoff scores that are provided by the creators of the instrument for each category of maltreatment (Bernstein \& Fink, 1998). The minimum scores to qualify were nine, eight, siz, ten, and eight for emotional abuse, physical abuse, sexual abuse, emotional neglect, and physical neglect, respectively (Bernstein \& Fink, 1998). The pervasiveness of maltreatment variable was created by summing across the five types of maltreatment to yield a possible score that ranged from zero to five reflect the number of different types of maltreatment each participant reported experiencing. Past studies have found pervasiveness of maltreatment to correlate with continuous subscale scores of the CTQ as well as total maltreatment severity. The pervasiveness variable has also been correlated with emotion regulation (Bowman et al., 2009; Walsh et al., 2011)

\section{Data Analytic Approach}

Correlations were first examined among the variables of interest - pervasiveness of maltreatment, sad-anxious and hostile emotions, and intent to control emotion during highly charged moments. Next, the extent to which negative emotion mediates the relationship between child maltreatment and effort to control emotion in later life was examined by following the recommendations of Preacher and Hayes (2008) for mediation analysis and using bootstrapping estimation methods to derive standard errors, confidence intervals, and significance levels.

\section{Results}

Means and standard deviations for pervasiveness of maltreatment, experience of negative emotion, and efforts to control emotion are presented in Table 1 by gender. Reflecting the oversampling of participants with maltreatment histories, men in the sample reported, on average, 
MALTREATMENT HISTORY, EMOTION, \& REGULATORY INTENT

that they had experienced 2.11 different types of maltreatment $(\mathrm{SD}=1.49)$. Women reported a higher average of 3.01 types of maltreatment $(\mathrm{SD}=1.69)$. The number of types of maltreatment ranged for both men and women from 0 to $5 ; 78.3 \%$ of women and $63 \%$ of men experienced at least two types.

Correlations among study variables are also presented in Table 1 by gender. Men's pervasiveness of maltreatment in childhood was positively associated with the intensity of their experience of hostile and sad-anxious emotions and their reported intention to control emotions during affectively charged moments of their interactions. Men's hostile and sad-anxious emotions were also highly correlated with each other and with reported intention to control emotion. Women's pervasiveness of maltreatment in childhood was positively associated with the intensity of their hostile feelings and with how much they reported trying to control emotion during interactions, but not with the intensity of their sad-anxious feelings. Women's feelings of hostility, sadness-anxiety, and intention to control emotion were all positively associated with oneanother.

Based on these correlations, we tested whether, for both men and women, the experience of hostile emotion during the couple interaction mediated the relationship between pervasiveness of maltreatment and trying to control emotion in the couple interaction (model 1). This same model was also tested with sad-anxious emotion as a mediator for men (model 2). The procedures and SPSS macro developed by Preacher and Hayes (2008) were used to assess mediation with non-parametric bootstrapping procedures.

Figures 1,2, and 3 show the regression coefficients for the mediational models. The association between pervasiveness of maltreatment and trying to control emotions in couple interactions was partially mediated by experience of hostile emotion for both men and women, as the 
MALTREATMENT HISTORY, EMOTION, \& REGULATORY INTENT

link between emotional maltreatment and trying to control emotion was reduced once intensity

of hostile emotions was included in the model. The association between men's pervasiveness of maltreatment and efforts to control emotion during the couple interaction was also partially mediated by men's experience of sad-anxious emotion in the interaction; the total effect, the direct effect of pervasiveness of maltreatment on intention to control emotion, and the indirect effect (through emotional arousal) were statistically significant in all three mediation models. These models explained a significant proportion of variance in intent to control emotion: Total $R^{2}$ for the models with men's hostile emotions, women's hostile emotion, and men's vulnerable emotions as mediators were $.55, .41$, and .30 , respectively.

\section{Discussion}

The long-term consequences of child maltreatment for interpersonal functioning are widely recognized by clinicians (Briere, Berliner, Bulkey, Jenny, \& Reid, 1996) and increasingly being documented through research (Colman \& Widom, 2004; DiLillo \& Long, 1999; Mullen et al., 1994; Webb \& Otto Whitmer, 2001). Heightened emotional experience and a perceived need to actively control these emotions may play a key role in explaining the link between early maltreatment and difficulties in adult interpersonal functioning, but this pathway of influence has not been extensively studied. The objective of this research was to examine links between a history of childhood maltreatment and emotional experiences and regulatory intentions during affectively salient moments of a challenging discussion with an intimate partner in adulthood. Results largely supported the hypothesis that pervasiveness of maltreatment in childhood is associated with the experience of more negative emotion and greater intent to control emotion in discussions with intimate partners about an upsetting incident. Moreover, analyses supported the idea 
MALTREATMENT HISTORY, EMOTION, \& REGULATORY INTENT

that negative emotional arousal mediated links between maltreatment history and intent to control emotion in these interactions.

We chose to focus on intent to control emotion in order to capture regulatory goals that might be connected to one's discomfort with negative emotional arousal. A number of emotion theorists have emphasized the importance of understanding an individual's goals when considering emotion regulatory efforts (e.g., Campos et al., 1989; Schulz \& Lazarus, 2012; Timmers et al., 1998). Emotion regulatory goals are likely to be shaped by an individual's personal history as well as by the particular situation that the individual encounters (Schulz \& Lazarus, 2012). Therefore, in this study we focused on childhood maltreatment as a key element of a person's history and on the degree of emotion arousal in a challenging discussion with an intimate partner as a particularly relevant proximal situation. The links between pervasiveness of maltreatment and more intense hostile feelings in both men and women, and more intense sadness and anxiety in men, are consistent with the idea that histories of child maltreatment are associated with greater negative emotional arousal in challenging interpersonal situations in adulthood. Consistent with previous studies (MacMillan et al., 2001, Wise et al., 2001), these results support the idea that experiencing increased levels of negative emotion is a sequela of child maltreatment that persists into adulthood (Polusny \& Follette, 1995; Paivio \& Laurent, 2001). The research examining potential long-term effects of child maltreatment on emotion processing in adulthood, including emotion comfort, perception, communication, interpretation, and regulation of emotion, is very limited (Widom \& Cahall, 2014), and our findings add to this body of research.

We hypothesized that victims of more types of child maltreatment would report stronger intentions to control their emotions as a result of experiencing heightened negative emotion during affectively-charged interactions with important others, an idea supported by the mediation 
MALTREATMENT HISTORY, EMOTION, \& REGULATORY INTENT

models examined in the current study. To our knowledge, this is the first study that examines the link between cumulative exposure to different forms of child maltreatment and emotion regulatory goals in adulthood. Findings add empirical support to clinical observation that individuals who were abused as children are more concerned than non-abused individuals with controlling negative emotion in close relationships (Linehan, 1993; Pavio \& Laurent, 2001). The link between the pervasiveness of childhood maltreatment and motivation to control emotion was partially mediated by the intensity of participants' experience of hostile emotions. Experience of sadanxious emotion also partially mediated the relationship between men's pervasiveness of maltreatment and stronger intention to control emotion during affectively charged moments of couple interaction.

Emotional arousal was only a partial mediator of links between pervasiveness of childhood maltreatment and intent to control emotions. In future research it will be important to consider what other factors may explain why maltreatment is connected with greater motivation to control emotions. One important possibility is that maltreatment history creates a greater sensitivity to and discomfort with negative emotion, so that maltreated individuals are more likely to engage regulatory efforts to dampen emotion even at low levels of emotion arousal. Evidence for this idea comes from past studies that have documented greater vigilance and sensitivity to negative emotion cues in individuals with a maltreatment history (Pollak \& Cicchetti, 2000; Pollak \& Sinha, 2002). Research on experiential avoidance (Harvey, Watkins, Mansell, \& Shafran, 2004; Hayes, Wilson, Gifford, Follette, \& Strosahl, 1996) suggests that a sensitivity to and discomfort with negative affect may underlie a number of different kinds of psychopathology and contribute to challenges in functioning in close relationships. Emotional exchanges are widely believed to be influential determinants of the quality and stability of intimate partnerships (Brad- 
MALTREATMENT HISTORY, EMOTION, \& REGULATORY INTENT

bury \& Fincham, 1987; Fincham \& Beach, 1999; Jacobson et al 1994; Waldinger, Schulz,

Hauser, Allen, \& Crowell, 2004). Difficulties in tolerating negative emotions, the experience of more intense negative emotions, and strong compulsions to dampen negative emotion are all likely to influence the adaptational significance of emotional exchanges in intimate relationships.

Our findings suggest that experiencing multiple forms of child maltreatment may have a cumulative effect on emotional regulatory efforts and emotional experiences in close adult relationships. This study underscores the importance of accounting for multiple types of child maltreatment when examining long-term sequelae (Clemmons et al., 2007, Higgins \& McCabe 2000, Walsh, 2011), rather than considering specific types of maltreatment (e.g., physical abuse) in isolation.

The focus in this study on the experience of emotions and intentions to control emotions in actual couple interactions is important. By capturing experiences and motivations as they unfold in the course of a challenging interaction, this study taps into important affective processes that are difficult to assess with global measures of functioning or self-reports of general emotional experience or motivation. Past research focusing on more distal or global indicators of functioning, such as psychopathology, has sometimes failed to find any long-term sequelae of maltreatment (Rind, Tromovitch, \& Bauserman, 1998). By measuring processes of emotion within intimate dyads through in-vivo reports of emotional experience during couple discussions, this study may capture more subtle psychological processes through which maltreatment has its enduring effects.

This study has limitations that are important to keep in mind. The sample was recruited with the goal of obtaining participants with varying levels of child maltreatment; therefore, levels of child maltreatment present in the current study are not representative of a normative commu- 
MALTREATMENT HISTORY, EMOTION, \& REGULATORY INTENT

nity sample. Study results should not be assumed relevant to a normative sample, but rather of specific importance to those who have experienced child maltreatment. Study findings relied on self-report measures asking participants to recall maltreatment in childhood. Although studies have supported the validity of historical reports using the CTQ (Bernstein et al., 1994; Bernstein et al., 2003), it is important to acknowledge the potentially limited accuracy of retrospective accounts of child maltreatment. Maltreatment histories were collected prior to but during the same laboratory visit as the videotaped couple interaction, raising the possibility that participants' state of mind influenced how they responded to both tasks. Moreover, the lack of temporal separation between the mediators (reports of emotion experience) and outcome (intentions to control emotion) that were the focus of this study is also a limitation. This lack of separation reflects the reality that emotional experience and efforts to manage that experience occur with little or no temporal separation in vivo. However, this lack of temporal separation must be borne in mind when interpreting the results of the mediation analyses.

The study raises additional issues that merit further investigation. It may be that the experience of hostile emotions in intimate interactions is equally threatening to men and women with histories of child maltreatment, but that the experience of more vulnerable emotions, like sadness and anxiety, is particularly unsettling for men, prompting greater efforts at emotional control. Further research would be needed to examine this possibility. The focus in this study on intent to control emotion captured an important element of emotion regulatory processes but the study did not assess directly individuals' emotion regulatory efforts. It would be informative in future research to attempt to capture participants' actual emotion regulation strategies, which might include methods such as avoidance through refusing to engage, changing the topic or diverting the conversation (Znoj, 2008). 
MALTREATMENT HISTORY, EMOTION, \& REGULATORY INTENT

The results of this study lend empirical support to the clinical observation that experiencing increased negative emotion and feeling a stronger need to control these emotions are particular challenges for those who have experienced more types of child maltreatment. These challenges likely contribute to interpersonal difficulties in adulthood (Colman \& Widom, 2004; Davis \& Petretic-Jackson, 2000), as individuals who are chronically sensitive to emotion often report having difficulties in relationships (Linehan, 1993), and individuals who struggle with overwhelming emotion often fail to communicate effectively with their partners (Kirby \& Baucom, 2007). The current study supports the importance of exploring in therapy how partners with histories of child maltreatment are affected by and try to manage strong affects in intimate relationships (Kirby \& Baucom, 2007; Linehan, 1993). 
MALTREATMENT HISTORY, EMOTION, \& REGULATORY INTENT

References

Arata, C., Langhinrichsen-Rohling, J., Bowers, D., \& O’Farrill-Swails, L. (2005). Single versus multitype maltreatment: An examination of the long-term effects of child abuse. Journal of Aggression, Maltreatment \& Trauma, 11, 29-52.

Bernstein, D. P., \& Fink, L. (1998). Childhood Trauma Questionnaire: A retrospective selfreport (pp. 68). San Antonio: The Psychological Corporation.

Bernstein, D. P., Fink, L., Handelsman, L., \& Foote, J. (1994). Initial reliability and validity of a new retrospective measure of child maltreatment and neglect. The American Journal of Psychiatry, 151(8), 1132-1136.

Bernstein, D. P., Stein, J. A., Newcomb, M. D., Walker, E., Pogge, D., Ahluvalia, T., .. . Zule, W. (2003a). Development and validation of a brief screening version of the Childhood Trauma Questionnaire. Child maltreatment \& Neglect, 27(2), 169-190. doi: 10.1016/s0145-2134(02)00541-0

Bowman, K., Rew, L., \& Murphey, C. (2009). Childhood maltreatment among community dwelling adult Latinas. Issues In Mental Health Nursing, 30(7), 443-450. doi:10.1080/01612840902722203

Bradbury, T. N., \& Fincham, F. D. (1987). Assessment of affect in marriage. In K. D. O'Leary (Ed.), Assessment of Marital Discord: An Integration for Research and Clinical Practice (pp. 59-108). Hillsdale, NJ: Erlbaum.

Briere, J., Berliner, L., Bulkey, J. A., Jenny, C., \& Reid, T. (1996). The APSAC handbook on child maltreatment. Thousand Oaks: Sage publication.

Briere, J., \& Runtz, M. (1989). The Trauma Symptom Checklist (TSC-33): Early data on a new scale. Journal of Interpersonal Violence, 4, 151-163.

Busby, D. M., Walker, E. C., \& Holman, T. B. (2011). The association of childhood trauma with perceptions of self and the partner in adult romantic relationships. Personal Relationships, 18(4), 547-561. doi: 10.1111/j.1475-6811.2010.01316.x

Campos, J.J., Campos, R.G., \& Barrett, K.C. (1989). Emergent themes in the study of emotional development and emotion regulation. Developmental Psychology, 25, 394-402.

Clemmons, J., Walsh, K., DiLillo, D., \& Messman-Moore, T. L. (2007). Unique and 
MALTREATMENT HISTORY, EMOTION, \& REGULATORY INTENT

combined contributions of multiple abuse types and abuse severity to adult trauma symptomatology. Child Maltreatment, 12, 172-181. doi:10.1177/ 107755950629824

Colman, R. A., \& Widom, C. S. (2004). Childhood maltreatment and neglect and adult intimate relationships: a prospective study. Child maltreatment \& Neglect, 28(11), 1133-1151. doi: 10.1016/j.chiabu.2004.02.005

Curtis, W., \& Cicchetti, D. (2013). Affective facial expression processing in 15-month old infants who have experienced maltreatment: An event-related potential study. Child Maltreatment, 18(3), 140-154.

Davis, E. L., Levine, L. J., Lench, H. C., \& Quas, J. A. (2010). Metacognitive emotion regulation: Children's awareness that changing thoughts and goals can alleviate negative emotions. Emotion, 10(4), 498-510. doi:10.1037/a0018428

Davis, J. L., \& Petretic-Jackson, P. A. (2000). The impact of child sexual maltreatment on adult interpersonal functioning: A review and synthesis of the empirical literature. Aggression and Violent Behavior, 5(3), 291-328. doi: http://dx.doi.org/10.1016/S1359$\underline{1789(99) 00010-5}$

DiLillo, D., \& Long, P. J. (1999). Perceptions of couple functioning among female survivors of child sexual abuse. Journal of Child Sexual Abuse, 7, 59-75.

Dodge, K. A., Pettit, G. S., Bates, J. E., \& Valente, E. (1995). Social information-processing patterns partially mediate the effect of early physical maltreatment on later conduct problems. J Abnorm Psychol, 104(4), 632-643.

Elliott, D. M., \& Briere, J. (1992). Sexual abuse trauma among professional women: Validating the Trauma Symptom Checklist-40. Child Abuse \& Neglect, 16, 391398

Emery, R. E. (1989). Family violence. American Psychologist, 44, 321-328.

English, D. J., Graham, J. C., Litrownik, A. J., Everson, M., \& Bangdiwala, S. I. (2005). Defining maltreatment chronicity: Are there differences in child outcomes? Child Abuse \& Neglect,29, 575-595.

Foa, E. B., Riggs, D. S., Dancu, C. V., \& Rothbaum, B. O. (1993). Reliability and 
validity of a brief instrument for assessing post-traumatic stress disorder. Journal of Traumatic Stress, 6, 459-473.

Felitti, V.J., Anda, R.F., Nordenberg, D., Williamson, D.F., Spitz, A.M., Edwards, V., Koss, M.P., Marks, J.S (1998). Relationship of childhood abuse and household dysfunction to many of the leading causes of death in adults: the adverse childhood experiences (ACE) study. American Journal of Preventive Medicine, $14: 245-258$.

Fincham, F. D., \& Beach, S. R. H. (1999). Conflict in marriage: Implications for working with couples. Annual Review of Psychology, 50, 47-77.

Frederick, J., \& Goddard, C. (2008). Living on an island: consequences of childhood maltreatment, attachment disruption and adversity in later life. Child \& Family Social Work, 13(3), 300-310. doi: 10.1111/j.1365-2206.2008.00554.x

Glaser, J., van Os, J., Portegijs, P. M., \& Myin-Germeys, I. (2006). Childhood trauma and emotional reactivity to daily life stress in adult frequent attenders of general practitioners. Journal Of Psychosomatic Research, 61(2), 229-236. doi:10.1016/j.jpsychores.2006.04.014

Gottman, J. (1994). An agenda for marital therapy. In S. Johnson \& L. Greenberg (Eds.), The Heart of the Matter: Perspectives on Emotion in Marital Therapy (pp. 256-293). New York: Brunner/Mazel Publishers.

Gottman, J., \& Levenson, R. (1985). A valid procedure for obtaining self-report of affect in marital interaction. Journal of Consulting and Clinical Psychology, 53(2), 151-160.

Gottman, J. M. (1994). What Predicts Divorce?: The Relationship Between Marital Processes and Marital Outcomes. Hillsdale, NJ: Lawrence Erlbaum Associates.

Harvey, A., Watkins, E., Mansell, W., \& Shafran, R. (2004). Cognitive Behavioural Processes Across Psychological Disorders: A Transdiagnostic Approach to Research and Treatment. Oxford University Press: Oxford, UK, pp. 365, ISBN 0-19-852888-4

Hayes, S. C., Wilson, K. W., Gifford, E. V., Follette, V. M., \& Strosahl, K. (1996). Experiential avoidance and behavioral disorders: A functional dimensional approach to diagnosis and treatment. Journal of Consulting and Clinical Psychology, 64(6), 1152-1168. 
Higgins, D. J., \& McCabe, M. P. (2000). Multi-type maltreatment and the long-term adjustment of adults. Child Abuse Review, 9, 6-18.

Hill, J. (2006). Child maltreatment and depression in adults: Implications for prevention. Clinical Neuropsychiatry: Journal of Treatment Evaluation, 3(1), 23-28.

Howe, D., \& Campling, J. (1995). Attachment Theory for Social Work Practice: Palgrave Macmillan Limited.

Ickes, W., Stinson, L., Bissonnette, V., \& Garcia, S. (1990). Naturalistic social cognition: Empathic accuracy in mixed-sex dyads. Journal of Personality \& Social Psychology, 59(4), 730-742.

Jacobson, N. S., Gottman, J. M., Waltz, J., Rushe, R., Babcock, J., \& Holtzworth-Munroe, A. (1994). Affect, verbal content, and psychophysiology in the arguments of couples with a violent husband. Journal of Consulting and Clinical Psychology, 62(5), 982-988.

Kinard, E. M. (1994). Methodological issues and practical problems in conducting research on maltreated children. Child Abuse \& Neglect, 18(8), 635-656.

Kirby, J. S., \& Baucom, D. H. (2007). Integrating Dialectical Behavior Therapy and CognitiveBehavioral Couple Therapy: A Couples Skills Group for Emotion Dysregulation. Cognitive and Behavioral Practice, 14(4), 394-405. doi: 10.1016/j.cbpra.2006.09.006

Kirby, J. S., \& Baucom, D. H. (2007). Treating emotion dysregulation in a couples context: a pilot study of a couples skills group intervention. J Marital Fam Ther, 33(3), 375-391.

Lau, A. S., Leeb, R. T., English, D., Graham, J. C., Briggs, E. C., Brody, K. E., et al. (2005). What's in a name? A comparison of methods for classifying predominant type of maltreatment. Child Abuse \& Neglect, 29, 533-551.

Linehan, M. (1993). Cognitive-behavioral treatment of borderline personality disorder: The Guilford Press.

Lorber, M. F. (2007). Validity of video-mediated recall procedures for mothers' emotion and child ratings. J Fam Psychol, 21(3), 520-528.

Luke, N., \& Banerjee, R. (2013). Differentiated associations between childhood maltreatment experiences and social understanding: A meta-analysis and systematic review. Developmental Review, 33(1), 1-28. doi:10.1016/j.dr.2012.10.001 
MacMillan, H. L., Fleming, J. E., Streiner, D. L., Lin, E., Boyle, M. H., Jamieson, E., . . . Beardslee, W. R. (2001). Childhood maltreatment and lifetime psychopathology in a community sample. The American Journal of Psychiatry, 158(11), 1878-1883. doi: 10.1176/appi.ajp.158.11.1878

Masten, C. L., Guyer, A. E., Hodgdon, H. B., McClure, E. B., Charney, D. S., Ernst, M., Kaufman, J., Pine, D. S., \& Monk, C. S. (2008). Recognition of facial emotions among maltreated children with high rates of post-traumatic stress disorder. Child Abuse \& Neglect, 32, 139-153.http://dx.doi.org/10.1016/j.chiabu.2007.09.006

Mullen, P. E., Martin, J. L., Anderson, J. C., Romans, S. E., \& Herbison, G. P. (1994). The effect of child sexual maltreatment on social, interpersonal and sexual function in adult life. $\mathrm{Br}$ J Psychiatry, 165(2), 35-47.

Ornduff, S. R. (2000). Childhood maltreatment and malevolence: Quantitative research findings. Clinical Psychology Review, 20(8), 997-1018. doi: http://dx.doi.org/10.1016/S0272$\underline{7358(99) 00021-5}$

Paivio, S. C., \& Laurent, C. (2001). Empathy and emotion regulation: Reprocessing memories of childhood maltreatment. Journal of Clinical Psychology, 57(2), 213-226. doi: 10.1002/1097-4679(200102)57:2<213::aid-jclp7>3.0.co;2-b

Paivio, S., \& McCulloch, C. (2004). Alexithymia as a mediator between childhood trauma and self-injurious behaviors. Child Abuse \& Neglect, 28, 339-354.

Pollak, S., Cicchetti, D., \& Klorman, R. (1998). Stress, memory, and emotion: Developmental considerations from the study of child maltreatment. Development and Psychopathology, 10(4), 811-828. doi: 10.1017/s0954579498001886

Pollak, S. D., Cicchetti, D., Hornung, K., \& Reed, A. (2000). Recognizing emotion in faces: Developmental effects of child abuse and neglect. Developmental Psychology, 36(5), 679688. doi:10.1037/0012-1649.36.5.679

Pollak, S. D. and P. Sinha (2002). "Effects of early experience on children's recognition of facial displays of emotion." Developmental Psychology 38(5): 784-791. 
Polusny, M. A., \& Follette, V. M. (1995). Long-term correlates of child sexual maltreatment: Theory and review of the empirical literature. Applied \& Preventive Psychology, 4(3), 143-166. doi: 10.1016/s0962-1849(05)80055-1

Preacher, K. J., \& Hayes, A. F. (2008). Asymptotic and resampling strategies for assessing and comparing indirect effects in multiple mediator models. Behavior Research Methods, 40(3), 879-891. doi: 10.3758/brm.40.3.879

Rellini, A. H., Vujanovic, A. A., Gilbert, M., \& Zvolensky, M. J. (2012). Childhood Maltreatment and Difficulties in Emotion Regulation: Associations with Sexual and Relationship Satisfaction among Young Adult Women. Journal of Sex Research, 49(5), 434-442. doi: $10.1080 / 00224499.2011 .565430$

Rind, B., Tromovitch, P., \& Bauserman, R. (1998). A meta-analytic examination of assumed properties of child sexual maltreatment using college samples. Psychological Bulletin, 124(1), 22-53.

Romens, S. E., \& Pollak, S. D. (2012). Emotion regulation predicts attention bias in maltreated children at-risk for depression. Journal Of Child Psychology And Psychiatry, 53(2), 120-127. doi:10.1111/j.1469-7610.2011.02474.x

Rossman, B. B. R., Hughes, H. M., \& Hanson, K. L. (1998). The victimization of school age children. Journal of Aggression, Maltreatment, and Trauma, 2, 87-106.

Sanford, K. (2007). Hard and soft emotion during conflict: Investigating married couples and other relationships. Personal Relationships, 14(1), 65-90. doi:10.1111/j.14756811.2006.00142.x

Schulz, M.S. \& Lazarus, R.S. (2012). Emotion regulation during adolescence: A cognitivemediational conceptualization. In P.K. Kerig, M.S. Schulz, \& S.T. Hauser (Eds.), Adolescence and beyond: Family processes and development (pp. 19-42). Oxford University Schulz, M. S., \& Waldinger, R. J. (2004). Looking in the mirror: Participants as observers of their own and their partners' emotions in marital interactions. In P. Kerig \& D. Baucom (Eds.), Couple observational coding systems (pp. 259-272). Hillsdale, NJ: Lawrence Erlbaum. 
Schulz, M. S., \& Waldinger, R. J. (2010). Capturing the elusive: Studying emotion processes in couple relationships. In M. S. Schulz, M. Pruett, P. K. Kerig, R. D. Parke (Eds.), Strengthening couple relationships for optimal child development: Lessons from research and intervention (pp. 131-147). Washington, DC US: American Psychological Association. doi:10.1037/12058-009

Shipman, K. L., Schneider, R., Fitzgerald, M. M., Sims, C., Swisher, L., \& Edwards, A. (2007). Maternal emotion socialization in maltreating and non-maltreating families: Implications for children's emotion regulation. Social Development, 16, 268285.

Tabachnick, B. G., \& Fidell, L. S. (2001). Using multivariate statistics: Allyn and Bacon.

Thomas, G., Fletcher, G., \& Lange, C. (1997). On-line empathic accuracy in marital interaction. Journal of Personality and Social Psychology, 72(4), 839-850.

Timmers, M., Fischer, A.H., \& Manstead, A.S.R. (1998). Gender differences in motives for regulating emotions. Personality and Social Psychology Bulletin, 2, 974-985.

Varia, R., Abidin, R. R., \& Dass, P. (1996). Perceptions of abuse: Effects of adult psychological and social adjustment. Child Abuse \& Neglect, 20, 511-526.

Vranceanu, A., Hobfoll, S. E., \& Johnson, R. J. (2007). Child multi-type maltreatment And associated depression and PTSD symptoms: The role of social support and stress. Child Abuse \& Neglect, 31(1), 71-84. doi:10.1016/j.chiabu.2006.04.010

Waldinger, R. J., \& Schulz, M. S. (2006). Linking hearts and minds in couple interactions: Intentions, attributions, and overriding sentiments. Journal of Family Psyhlogy, 20(3), 494504. doi: 10.1037/0893-3200.20.3.494

Waldinger, R. J., Schulz, M. S., Hauser, S. T., Allen, J. P., \& Crowell, J. A. (2004). Reading others' emotions: The role of intuitive judgments in predicting marital satisfaction, quality, and stability. Journal of Family Psychology, 18(1), 58-71. doi: 0.1037/0893-3200.18.1.58

Walsh, K., Gonsalves, V. M., Scalora, M. J., King, S., \& Hardyman, P. L. (2011). Child maltreatment histories among female inmates reporting inmate on inmate sexual victimization in prison: The mediating role of emotion dysregulation. Journal of Interpersonal Violence. doi:10.1177/0886260511421670. 
Watson, D., Clark, L. A., \& Tellegen, A. (1988). Development and validation of brief measures of positive and negative affect: The PANAS scales. Journal of Personality and Social Psychology, 54, 103-1070.

Webb, M., \& Otto Whitmer, K. J. (2001). Maltreatment History, World Assumptions, and Religious Problem Solving. Journal for the Scientific Study of Religion, 40(3), 445-453. doi: 10.1111/0021-8294.00068

Widom, C. S. (1999). Posttraumatic stress disorder in maltreatmentd and neglected children grown up. The American Journal of Psychiatry, 156(8), 1223-1229.

Widom, C. S., \& Ames, M. A. (1994). Criminal consequences of childhood sexual victimization. Child Abuse \& Neglect, 18, 303-318.

Wise, L. A., Zierler, S., Krieger, N., \& Harlow, B. L. (2001). Adult onset of major depressive disorder in relation to early life violent victimisation: a case-control study. Lancet, 358(9285), 881-887.

Zimmerman, M., Sheeran, T., \& Young, D. (2004). The Diagnostic Inventory for Depression: A Self-Report Scale to Diagnose DSM-IV Major Depressive Disorder. Journal Of Clinical Psychology, 60(1), 87-110. doi:10.1002/jclp.10207

Zlotnick, C., Zakriski, A. L., Shea, M. T., Costello, E., Begin, A., Pearlstein, T., \& Simpson, E. (1996). The long-term sequelae of sexual abuse: Support for a complex posttraumatic stress disorder. Journal of Traumatic Stress, 9, 195-205.

Znoj, H. J. (2008). Regulation emotionaler Prozesse in Psychotherapie und Verhaltensmedizin. Bern: Peter Lang. 